\title{
Differential diagnosis of three common Ixodes spp. ticks infesting songbirds of Western Europe: Ixodes arboricola,
}

\section{I. frontalis and I. ricinus}

Dieter Heylen $^{\mathrm{a}}{ }^{\square}$, Eliane De Coninck ${ }^{\mathrm{b}}$, Famke Jansen ${ }^{\mathrm{c}}$, Maxime Madder ${ }^{\mathrm{c}, \mathrm{d}}$

${ }^{a}$ Evolutionary Ecology Group, Department of Biology, University of Antwerp, Belgium

${ }^{\mathrm{b}}$ Royal Museum for Central Africa, African Zoology, Entomology, Chaussé e de Louvain 13, 3080 Tervuren, Belgium

${ }^{\mathrm{c}}$ Unit of Vector Biology, Department of Biomedical Sciences, Institute of Tropical Medicine, Nationalestraat 155, 2000 Antwerp, Belgium

${ }^{\mathrm{d}}$ Department of Veterinary Tropical Diseases, Faculty of Veterinary Science, University of Pretoria, Onderstepoort, Pretoria 0110, South Africa

\section{Corresponding author:}

University of Antwerp, Groenenborgerlaan 171, 2020 Antwerpen (Belgium)

Tel. : +32 326534 56, Fax. : +3232653474

E-mailaddress: Dieter.Heylen@uantwerpen.be 


\section{Abstract}

The three most common Ixodes spp. ticks found on songbirds in Western Europe are Ixodes frontalis, I. arboricola and I. ricinus. As the latter species is a generalist, it shares several avian hosts with the two strictly ornithophilic species. Infestations of the three species can overlap in time and space, implying that tick-borne pathogens maintained by the ornithophilic ticks and their hosts could be bridged by I. ricinus to non-avian hosts. Whereas the endophilic Ixodes arboricola only occurs in cavities, I. frontalis has been collected frequently by flagging methods from understory vegetation, which is also the habitat of the fielddwelling I. ricinus. As the latter two species have rather similar morphological characteristics, they can easily be confused with each other. In this study, we present scanning electron photomicrographs of all developmental stages of $I$. arboricola and $I$. frontalis, and provide a differential diagnosis key to distinguish the ornithophilic ticks from $I$. ricinus. In addition, we interpreted their phylogenetic associations based on mitochondrial 16S rDNA with other Ixodes spp. ticks (I. lividus, I. turdus, I. brunneus, I. vespertilionis, I. trianguliceps, I. hexagonus, I. scapularis).

Key words: Ixodes frontalis, Ixodes arboricola, Ixodes ricinus, Borrelia burgdorferi s.1., Lyme disease, Rickettsia, 16S rDNA

Corresponding author: Dieter Heylen, Groenenborgerlaan 171, 2020 Antwerpen (Belgium), tel : +32 326534 70, Fax : +32 326534 74, E-mail:

Dieter.Heylen@uantwerpen.be 


\section{Introduction}

There is growing interest in medical parasitology for host-specialized ticks that support enzootic cycles of pathogens with economic importance (Bown et al., 2006; Norte et al., 2013b; Piesman and Gern, 2004). Although these ticks generally do not infest humans and livestock, their hosts are often shared by generalist ticks that do. Consequently, pathogens of host-specialized ticks may be bridged via generalist ticks to other hosts outside the enzootic cycles (Gomez-Diaz et al., 2010; Gray, 1998; Piesman and Gern, 2004). To gain insight into the epidemiology of tick-borne pathogens and their vectors, and to do research on ticks in general, correct species identification is all the more crucial. Morphological identification of ticks is not straightforward, as it requires expertise, good identification keys and reference material.

In the scope of our study on the ecology of the ornithophilic ticks I. arboricola Schulze and Schlottke 1929 and I. frontalis Panzer 1798, we reviewed the scientific literature on Ixodes spp. ticks infesting European songbirds. We found that the identification keys seldom cover all developmental stages, and their availability is often limited (Arthur, 1963; Hillyard, 1996; Manila, 1998; Van Bronswijk et al., 1979). Furthermore, immature developmental stages of the latter species have seldom been illustrated, in particular unfed individuals that are not damaged, but also adult males (Arthur, 1953; Bona and Stanko, 2013; Lundqvist et al., 1998). Ixodes arboricola is a nidicolous tick of cavity-nesting birds. The tick's off-hos t environments are cavities, where it infests birds that roost and breed (Arthur, 1963; Hillyard, 1996) and where it detaches after feeding (Heylen and Matthysen, 2010; White et al., 2012). It is of potential significance for the epidemiology of tick-borne pathogens, as the tick carries Rickettsia sp. and Borrelia burgdorferi s.1. bacteria (Heylen et al., 2013b; Spitalska et al., 2011; Thorud, 1999) and shares several host species with the main European vector of tick- 
borne diseases in humans and animals, I. ricinus (L.) (Heylen et al. (in press); Hillyard, 1996; Jongejan and Uilenberg, 2004). Ixodes frontalis is also considered to be associated with bird nests (Hillyard, 1996) and infests a broad range of terrestrial birds, including songbirds that breed in the open (e.g. thrushes, Turdidae). It also carries several pathogenic agents, including B. burgdorferi s.l. bacteria, 'Candidatus Neoehrlichia mikurensis' and Chizé virus (Chastel et al., 1999; Doby, 1998; Estrada-Peñ a et al., 1995; Heylen et al., 2013b; Movila et al., 2013; Norte et al., 2013a; Norte et al., 2013b). Although this tick has been collected by flagging methods on understory vegetation (Bona and Stanko, 2013; Doby, 1998; Gilot et al., 1997; Schorn et al., 2011) and is widely spread over Europe (Hillyard, 1996), it has been rarely diagnosed, most likely because of its morphological resemblance with the very abundant $I$. ricinus.

In our study, we address a problem related to the identification of Ixodes spp. ticks that are commonly found on many songbirds of Western Europe, compiling the scattered available information, supplemented by new reference material of all developmental stages. The two main objectives of the paper are: 1) to present high quality scanning electron photomicrographs (SEM) of the different developmental stages of the ornithophilic ticks (I. arboricola and I. frontalis) to facilitate morphological comparison with the generalist $I$. ricinus, 2) to provide a differential diagnosis key to distinguish the ornithophilic ticks from the generalist tick I. ricinus.

We validate the specimens' identity, by comparing genetic sequences (mitochondrial $16 \mathrm{~S}$ rDNA) with those available in GenBank. In addition, the sequences are used to construct a phylogenetic tree including some other Ixodes spp. species commonly found on songbirds in the Holarctic region (I. lividus, I. turdus, I. brunneus, I. scapularis) and on mammals in Europe (I. vespertilionis, I. trianguliceps, I. hexagonus). 


\section{Material and methods}

\section{Collection of ticks}

Ixodes frontalis: Larvae of two egg batches obtained from I. frontalis adult females that were derived from a mail box in 2008 in which great tits (Parus major L.) had bred were exposed to great tits, successfully attached and engorged. After detachment, the ticks moulted to the nymphal developmental stage. Similarly, the adult stages were obtained from nymphs that fed on great tits, and moulted. Ixodes arboricola: The ticks used here originated from a laboratory colony originally collected during the winter of 2007-2008 from nest boxes in the north of Belgium (for details, see Heylen et al., 2012b) in which great and blue tits (Cyanistes caeruleus L.) breed and roost. Ticks were bred on great tits and blue tits. Ixodes ricinus: All developmental stages were collected in 2012 by dragging a white flannel flag over suitable understory vegetation (Heylen et al., 2010). The collected ticks were identified using a stereo-microscope, identification keys (Hillyard, 1996; Manila, 1998; Van Bronswijk et al., 1979) and descriptions (Arthur, 1953, 1963).

\section{DNA extraction and PCR}

DNA extraction was based on the method of Boom et al. (1990). Ticks, preserved in ethanol, were allowed to air dry prior to being cut in two or having two legs removed for extraction, using a scalpel blade. The tick material was placed in a $1.5 \mathrm{ml}$ microcentrifuge tube and 180 $\mu$ ATL buffer (Qiagen) and $20 \mu$ Proteinase $\mathrm{K}$ were added. The tubes were incubated overnight at $56^{\circ} \mathrm{C}$, while shaking. The process continued the next morni ng by first adding 200 $\mu \mathrm{AL}$ buffer (Qiagen), mixing and incubation for 10 minutes at $70{ }^{\circ} \mathrm{C}$, followed by $40 \mu$ of 
diatomaceous earth suspension and incubation for one hour at $37^{\circ} \mathrm{C}$ while s haking. The tubes were centrifuged for 20 seconds and supernatant was discarded. The pellet was washed three times, twice with $900 \mu \mathrm{l} 70 \%$ ethanol and once with $900 \mu \mathrm{l}$ acetone. Wa shing involved adding ethanol or acetone, mixing, centrifuging for $4 \mathrm{~s}$ and discarding supernatant. The pellet was dried in the thermoblock at $50^{\circ} \mathrm{C}$ for 20 min. $90 \mu \mathrm{TE}$ buffer was added to the pellet and incubated for $20 \mathrm{~min}$ at $60^{\circ} \mathrm{C}$ in the thermoblock, while shaking. The t ubes were centrifuged for $40 \mathrm{~s}$ and supernatant was transferred to a new microcentrifuge tube. The DNA extracts were stored at $-20^{\circ} \mathrm{C}$.

The mitochondrial 16S rDNA gene was amplified using the forward primer m16sFW/tck (5'CCG-GTC-TGA-ACT-CAG-ATC-AAG-T-3') and the reverse prim er m16sRev/tck (5'-GCTCAA-TGA-TTT-TTT-AAA-TTG-CTG-T-3'), both described in Mangold et al. (1998). PCR was carried out in a $25 \mu$ reaction volume, containing $1 \mu$ yellow sub (GENEO Bioproducts, Hamburg, Germany), $11 \mu \mathrm{MqW}, 5 \mu$ x GoTaq Flexi buffer (Promeg a), $1.65 \mathrm{mM} \mathrm{MgCl2}$, $0.2 \mathrm{mM}$ of the four dNTP's, $10 \mathrm{pM}$ of each primer, $1 \mathrm{U}$ Taq polymerase enzyme (Promega) and $5 \mu$ of the extracted DNA. A negative control was included. The PCR reaction was run in a programmable thermocycler (Biometra, Westburg) and the temperature profile consisted of a denaturation step at $94{ }^{\circ} \mathrm{C}$ for 4 minutes, followed by 35 cycles of $30 \mathrm{~s}$ at $92{ }^{\circ} \mathrm{C}, 30 \mathrm{~s}$ at $50^{\circ} \mathrm{C}$ and $45 \mathrm{~s}$ at $72{ }^{\circ} \mathrm{C}$ and an extension step of $8 \mathrm{~min}$ at $72{ }^{\circ} \mathrm{C}$.

PCR products were examined by loading $5 \mu$ of the product mixed with $2 \mu$ of loading buffer (Thermo Scientific) onto 2\% agarose gels (Sigma), together with a 100bp DNA ladder (Thermo Scientific). The samples were run for $20 \mathrm{~min}$ at $100 \mathrm{~V}$, stained in ethidium bromide for 30 minutes and photographed under UV illumination. 


\section{Cloning and sequencing}

PCR products were purified using the QIAquick PCR purification kit (Qiagen) and subsequently cloned with Topo TA Cloning® Kit with One Shot ${ }^{\circledR}$ TOP10 E. coli (Invitrogen). Sequences were confirmed by sequencing by the VIB genetic service facility (University of Antwerp), using the ABI PRISM®BigDye ${ }^{\mathrm{TM}}$ Terminator cycle sequencing kit and a capillary DNA sequencer (Applies Biosystems 3730XL DNA Analyzer). DNA sequencing was performed in both directions.

\section{Sequence analysis}

For each of the ticks, the obtained sequence results were blasted against conspecific sequences available in GenBank. The obtained sequences were aligned using SerialCloner (2.6.1) and the aligned sequences were further analyzed using Jalview (14.0) to build a phylogenetic tree (average distance using \% identity) with sequences from $I$. turdus, $I$. brunneus, I. vespertilionis, I. hexagonus and I. scapularis obtained from GenBank. In addition, sequences of I. lividus Koch 1844 (collected in 2013 from mist-net captured bank swallows (Riparia riparia L.)) and I. trianguliceps Birula 1895 (collected in 2012 by flagging methods on forest understory vegetation) were included in the analysis. Rhipicephalus appendiculatus Neumann 1901 was used as outgroup, as it is related to the Ixodes spp. tick species, but less closely than any other Ixodes spp. species is to another (cf. Mangold et al., 1998). 


\section{Scanning electron microscopy (SEM):}

Prior to drying and scanning, field ticks were cleaned in an ultrasound bath to remove all dust and impurities. Hexamethyldisilazane was used for the chemical drying of the specimens. Prior to examination with a Jeol $6480 \mathrm{LV}$ electron scanning microscope, the specimens were gold coated with a Jeol JFC-1300 Auto fine Coater. All scanning images were taken in the high voltage mode.

\section{Results}

\section{Morphological identification}

For topological terminology, as well as the general characteristics for the identification of different stages and sexes, we refer to Hillyard (1996). In brief, larvae have three pairs of legs, while all other stages have four. Larvae, nymphs and adult females have a scutum that is restricted to the anterior part of the dorsum, while adult males have a scutum that covers the entire dorsum. Adult females are distinguished from nymphs by the presence of the genital opening and the presence of porose areas on the dorsum of the basis capituli.

For the identification of the three tick species we constructed the key below. Figures 1-3 illustrate the main morphological characteristics.

\section{Larvae}

1) Internal spur on coxa I present; all coxae have distinct external spurs. Auriculae are triangular shaped. $=>2$ 
Spurs and auriculae lacking (Fig. $1-\mathrm{C} 2$ and Fig. 2-C4). => I. arboricola

2) Front margin of the basis between palp and hypostome forms a forwardly directed protuberance (Fig. 2 -B4; see also illustrations of Arthur (1953)). Internal spur of coxa I small; external and internal spurs of coxa I equal in size (Fig. 1 -B2). => $I$. frontalis

Front margin between hypostome and palps is smooth and rounded (Fig. 2-A4). The length of the internal spur of coxa I is greater than the external spur (Fig. $1-\mathrm{A} 2)$. =>

\section{I. ricinus}

\section{Nymphs}

1) Internal spur on coxa I present; all coxae have distinct external spurs. Auriculae are triangular shaped $=>2$

Spurs and auriculae lacking. Palps and hypostome stubby. Apically truncated hypostome (Fig. $1-\mathrm{C} 1$ and Fig. $2-\mathrm{C} 3) \Rightarrow$ I. arboricola

2) The implantation of the hypostome on the basis of the capitulum (i.e. the transition from hypostome to palps) is abruptly stepped (Fig. 2 -B3). The angl e of the inner margins of the internal spurs is large (almost $90^{\circ}$ ), leading to a blunt-shaped internal spur. The external and internal spurs of coxa I are almost equal in size (Fig. 1 -B1). Palps are club-like and strongly narrowed at the base of article II, division between palp articles II and III is vague (Fig. 2 - B3). Apically pointed hypostome $=>\boldsymbol{I}$.

\section{frontalis}

The transition towards the palps is smooth and rounded (Fig. 2-A3) The length of the internal spur of coxa I is moderate in size, however still larger than the external spur (Fig.1 -A1). The shape of the internal spur is pointed. C lear division between 
articles II and III (situated in the middle of the palp). Article II slowly narrows towards article I (Fig. $2-\mathrm{A} 3) . \Rightarrow$ I. ricinus

\section{Adult males}

1) External spurs present on all coxae. $=>2$

Spurs absent (Fig. 1-C3). Ventral plates: length median plates equals length adanal plates. Pre-genital plate very small (Fig. 3-C2). Tar sus I profile abruptly humped near apex (Fig. 3-C1). => I. arboricola

2) No internal spurs (Fig. 1 -B3). Lacking division between palp articles II and III (Fig. $2-\mathrm{B} 1)$. Ventral plates: median plate more than twice 1 ength of adanal plates. Pregenital plate slightly longer than broad (Fig. 3-B2). Tars us I profile tapers gradually (Fig. 3 -B1). => I. frontalis

Very long internal spur (Fig. 1-A3). Palps with clear div ision between articles II and III (Fig. 2-A1). Pre-genital plate nearly twice as long as broad (Fig. 3-A2). => I. ricinus

\section{Adult females}

1) Prominent internal spur on coxa I; external spurs present on all coxae $=>\mathbf{2}$ Spurs absent (Fig. 1-C4). Auriculae almost absent. Pal ps and hypostome short. Apically truncated hypostome (Fig. 2-C2). Tarsus I profile abruptly humped near apex $($ cf. adult males $)=>$ I. arboricola

2) Coxa I with pointed internal spur, and blunt external spur. The external and internal spurs of coxa I are almost equal in size (Fig. 1 -B4). P alps and pointed hypostome 
long (longer than width of basis in between palps). Auriculae form blunt protuberances (Fig. 2 -B2). Tarsus I profile tapers gradually (cf. adult males) $=>\boldsymbol{I}$. frontalis

Coxa I with pointed internal and external spur. The internal spur is longer than the external spur (Fig. 1-A4). Palps and hypostome long (longer than width of basis). Apically rounded hypostome. Auriculae greatly reduced (Fig. 2-A2). Tarsus I profile tapers gradually (cf. adult males) $=>$ I. ricinus

\section{Sequence analysis of mitochondrial 16S rDNA}

Accession numbers of the sequences submitted to GenBank are listed in Table 1. The length of the obtained sequences varied from 414 to 462 bp. For each tick, the obtained sequences were blasted against sequences available in GenBank. For the sequence of $I$. arboricola, a $100 \%$ similarity (query cover of $89 \%$ ) was found in GenBank for the same species. Also for $I$.

frontalis (similarity 99\%, query cover 96\%) and I. ricinus (similarity: 100\%, query cover: 96\%) a high similarity was found with specimens in GenBank.

In the phylogenetic tree (Fig. 4), the sequences obtained from two I. ricinus individuals clustered together with the I. ricinus sequence from GenBank (L34292.1). Also the sequences from the I. frontalis and I. arboricola individuals showed a high similarity with the I. frontalis (AF549839.1) and I. arboricola (JF791813) sequences. All the obtained sequences were submitted to GenBank, including mitochondrial 16S rDNA from Belgian $I$. lividus and I. trianguliceps specimens. 


\section{Discussion}

For all scanned ornithophilic ticks, the 16S rDNA sequences of colony siblings matched with the conspecific sequences obtained from GenBank, validating the morphological identification of the specimens. The differential diagnosis presented here confirms that the three ticks are morphologically distinctive species that can be distinguished from each other with high confidence. It is important to mention that awareness of the natural morphological variation among conspecifics is essential for correct identification. I. arboricola, in particular, has proven to be exceptionally variable in its morphology (Haarlov, 1962), which could be an indication of the existence of different host races in this species. The illustrated characteristics of I. frontalis are also relevant for research on I. ricinus. Identification of the immature developmental stages of $I$. ricinus has proven to be problematic in comparison to $I$. frontalis (Arthur, 1953; Heylen et al., 2012a; Laakkonen et al., 2009; Laakkonen et al., 2012; Lundqvist et al., 1998). Moreover, both the ground-dwelling I. ricinus as well as I. frontalis individuals have been captured frequently by flagging methods in their shared habitats (Bona and Stanko, 2013; Doby, 1998; Gilot et al., 1997; Schorn et al., 2011). The collection of $I$.

frontalis from understory vegetation, the pronounced questing behavior on leaf-like substrates (cf. I. brunneus (Goddard, 2013a); D. Heylen, unpublished data) and diurnal detachment from diurnally active birds (cf. I. ricinus (Heylen and Matthysen, 2010); D. Heylen, unpublished data) all suggest that this tick species tends to be exophilic (Filippova, 1977) rather than endophilic (Hillyard, 1996).

The 16S rDNA sequence of I. arboricola was closely linked to that of the bank swallow tick (I. lividus) (Fig. 4). The sequences of I. frontalis showed a high similarity with the sequence of the same species originating from England (Xu et al., 2003) but also with the North- 
American I. brunneus (Goddard, 2008) and I. turdus from Nepal (Xu et al., 2003). Although we cannot assume causal relationships between the genetic similarities among ticks and their behavioral and phenotypic characteristics, within both clusters of tick species there are morphological and ecological resemblances. Ixodes arboricola and I. lividus are strictly endophilic ticks, associated with bird nests inside cavities in wooden and sandy substrates, respectively (Balashov, 1972; Hillyard, 1996). Both species have a low health impact on their songbird hosts (Heylen and Matthysen, 2011a; Szé p and Mdler, 2000). Ixodes frontalis, I. brunneus and I. turdus have a much broader host range, infesting both cavity-nesting and open-nesting birds (Arthur, 1953; Fukunaga et al., 1996; Goddard et al., 2013b). Ixodes frontalis and I. brunneus have been captured frequently from understory vegetation (Bona and Stanko, 2013; Doby, 1998; Gilot et al., 1997; Goddard et al., 2013b; Schorn et al., 2011). In a previous study, morphological comparison of the latter species by SEM revealed only minimal differences (Homsher and Sonenshine, 1977). Both tick species can have a strong health impact on their hosts, by causing avian tick paralysis - a syndrome characterized by birds showing acute depression or death due to secreted tick toxins (Luttrell et al., 1996; Monks et al., 2006).

Ixodes arboricola is a strictly endophilic tick of cavities, and hence is unlikely to encounter humans. This contrasts with I. frontalis and the related I. turdus (Fig. 4) that, due to their exophilic ecologies, can come in direct contact with humans on which they are able to attach (Gilot et al., 1997; Woo et al., 1990; Yasuma et al., 2013). To further assess the importance of I. arboricola and I. frontalis as vectors of pathogens to humans, experimental studies are required to evaluate their vector-competence, i.e. the capacity to carry and transmit pathogens to new hosts. An experimental study, investigating the transmission capability for $B$. burgdorferi s.l. spirochetes, found no evidence for successful transmission in the great tit (Parsus major) (Heylen et al., 2013a). However, transmission outcomes may differ for other 
pathogen-tick-host combinations, e.g. Borrelia turdi that has been frequently found in $I$. frontalis collected from thrushes (Turdidae) (Norte et al., 2013a,b), and Rickettsia species that have been detected in I. arboricola derived from cavity-nesting songbirds (Spitalska et al., 2011).

\section{Acknowledgments}

Dieter Heylen is a postdoctoral fellow of the Fund for Scientific Research -Flanders (FWO). The funders had no role in study design, data collection and analysis, decision to publish, or preparation of the manuscript. The authors have declared that no competing interests exist.

\section{References}

Arthur, D.R., 1953. The immature stages of Ixodes frontalis Panzer 1795. Parasitology 43, $175-177$.

Arthur, D.R., 1963. British ticks. Butterworths, London.

Balashov, Y.S., 1972. Bloodsucking ticks (Ixodidea) - vectors of dis eases of man and animals. Miscellaneous Publications of the Entomological Society of America 8, 159-376.

Bona, M., Stanko, M., 2013. First records of the tick Ixodes frontalis (Panzer, 1795) (Acari, Ixodidae) in Slovakia. Ticks Tick Borne Dis. 4, 478-481.

Boom, R., Sol, S.J., Salimans, M.M., Jansen, C.L., Wertheim-van-Dillen, P.M., van der

Noordaa, J., 1990. Rapid and simple method for purification of nucleic acids. J. Clin.

Microbiol. 28, 495. 
Bown, K.J., Begon, M., Bennett, M., Birtles, R.J., Burthe, S., Lambin, X., Telfer, S., Woldehiwet, Z., Ogden, N.H., 2006. Sympatric Ixodes trianguliceps and Ixodes ricinus ticks feeding on field voles (Microtus agrestis): Potential for increased risk of Anaplasma phagocytophilum in the United Kingdom? Vector Borne Zoon. Dis. 6, 404-410.

Chastel, C., Chandler, L., Le Goff, F., Chastel, F.O., Tesh, R., Shope, R., 1999. Chizé virus, a new phlebovirus isolated in France from Ixodes (Trichotoixodes) frontalis. Acta Virol. 43, 276-283.

Doby, J.M., 1998. Contribution àla connaissance de la biologie de Ixodes (Trichotoixodes) pari Leach (= I. frontalis (Panzer)) (Acari: Ixodidae), tique spé cifique des oiseaux. Acarologia 39, 315-325. Estrada-Peñ a, A., Oteo, J.A., Estrada-Peñ a, R., Gortá ær, C., Osá car, J.J., Moreno, J.A., Castellá , J., 1995Borrelia burgdorferi sensu lato in ticks (Acari: Ixodidae) from two different foci in Spain. Exp. Appl. Acarol. 19, 173-180.

Filippova, N.A., 1977. Fauna of the USSR. 4. Chelicerata. Ixodid ticks of the Subfamily Ixodinae., Nauka, Leningrad. (in Russian).

Fukunaga, M., Hamase, A., Okada, K., Inoue, H., Tsuruta, Y., Miyamoto, K., Nakao, M., 1996. Characterization of spirochetes isolated from ticks (Ixodes tanuki, Ixodes turdus, and Ixodes columnae) and comparison of the sequences with those of Borrelia burgdorferi sensu lato strains. Appl. Environ. Microbiol. 62, 2338-2344.

Gilot, B., Beaucournu, J.C., Chastel, C., 1997. Fixing on man of Ixodes (Trichotoixodes) frontalis (Panzer, 1795) collected with the flagging method. Parasite-Journal De La Societe Francaise De Parasitologie 4, 197-199.

Goddard, J. (2008). The bird tick, Ixodes brunneus Koch (Acari: Ixodidae): a rare and unusual tick in Mississippi. J. Mississippi Acad. Sci, 54, 246-249. 
Goddard, J., 2013a. Observations on questing activity of adult Ixodes brunneus Koch (Acari: Ixodidae) in Mississippi, J. Parasitol. 99, 346-349

Goddard, J., Goltz, L., Robbins, R.G., 2013b. New records of immature Ixodes brunneus Koch (Acari: Ixodidae) from Mississippi, U.S.A.. J. Vector Ecol. 38, 415-416.

Gomez-Diaz, E., Boulinier, T., Sertour, N., Cornet, M., Ferquel, E., McCoy, K.D., 2010. Genetic structure of marine Borrelia garinii and population admixture with the terrestrial cycle of Lyme borreliosis. Environ. Microbiol. 13, 2453-2467.

Gray, J.S., 1998. The ecology of ticks transmitting lyme borreliosis. Exp. Appl. Acarol. 22, 249-258.

Haarlov, N. , 1962. Variation in ixodid tick, Ixodes arboricola Schulze and Schlottke 1929. Parasitology 52, 425-439.

Heylen, D., Jacobs, I., Matthysen, E., Madder, M., 2012a. Comments on article 'First report of Ixodes frontalis (Acari: Ixodidae) in Finland, an example of foreign tick species transported by a migratory bird"(Memoranda Soc. Fauna Flora Fennica 85:16-19. 200 9). Mem. Soc. Fauna Flora Fennica 88, 19-20.

Heylen, D., Sprong, H., van Oers, K., Fonville, M., Leirs, H., Matthysen, E., 2013a. Are the specialized bird ticks, Ixodes arboricola and I. frontalis, competent vectors for Borrelia burgdorferi sensu lato? Environ. Microbiol. - doi: 10.1111/1462-2920.12332 Heylen, D., Tijsse, E., Fonville, M., Matthysen, E., Sprong, H., 2013b. Transmission dynamics of Borrelia burgdorferi s.1. in a bird tick community. Environ. Microbiol. 15, 663673.

Heylen, D.J.A., Madder, M., Matthysen, E., 2010. Lack of resistance against the tick Ixodes ricinus in two related passerine bird species. Int. J. Parasitol. 40, 183-191. Heylen, D.J.A., Matthysen, E., 2010. Contrasting detachment strategies in two congeneric ticks (Ixodidae) parasitizing the same songbird. Parasitology 137, 661-667. 
Heylen, D.J.A., Matthysen, E., 2011a. Differential virulence in two congeneric ticks infesting songbird nestlings. Parasitology 138, 1011-1021.

Heylen, D.J.A., Van Oosten, A.R., Devriendt, N., Elst, J., De Bruyn, L., Matthysen, E., in press. Seasonal feeding activity of the tree-hole tick, Ixodes arboricola. Parasitology Heylen, D.J.A., White, J., Elst, J., Jacobs, I., van de Sande, C., Matthysen, E., 2012b. Nestling development and the timing of tick attachments. Parasitology 139, 766-773.

Hillyard, P.D., 1996. Ticks of North-West Europe. Field studies council in association with the natural history museum, London. (Synopses of the British Fauna NewSeries) 52.

Homsher, P.J. and Sonenshine, D.E., 1977. Scanning electron microscopy of ticks for systematic studies 2. Structure of Haller's organ in Ixodes brunneus and Ixodes frontalis. J. Med. Entomol. 14, 93-97.

Jongejan, F., Uilenberg, G., 2004. The global importance of ticks. Parasitology 129, S3-S14. Laakkonen, J., Terhivua, J., Huhtamo, E., Vapalahti, O., Uzcá tegui, N.Y., 2009. First report of Ixodes frontalis (Acari: Ixodidae) in Finland, an example of foreign tick species transported by a migratory bird. Mem. Soc. Fauna Flora Fennica 85, 16-19.

Laakkonen, J., Terhivuo, J., Huhtamo, E., Vapalahti, O., Uzcátegui, N.Y., 2012. A response to the comments by Heylen et al. in the preceeding article. Mem. Soc. Fauna Flora Fennica $88,21$.

Lundqvist, L., Gray, J.S., Hillyard, P.D., 1998. Ixodes frontalis on the Baltic island of Gotland, Sweden. Med. Vet. Entomol. 12, 215-216.

Luttrell, M.P., Creekmore, L.H., Mertlns, J.W., 1996. Avian tick paralysis caused by Ixodes brunneus in the Southeastern United States. J. Wildlife Dis. 32, 133-136.

Mangold, A.J., Bargues, M.D., Mas-Coma, S., 1998. Mitochondrial 16S rDNA sequences and phylogenetic relationships of species of Rhipicephalus and other tick genera among Metastriata (Acari: Ixodidae). Parasitol. Res. 84, 478-484. 
Manilla, G., 1998. Fauna d' Italia: Acari, Ixodida. Edizioni Calderini, Bologna

Monks, D., Fisher, M., Forbes, N.A., 2006. Ixodes frontalis and avian tick-related syndrome in the United Kingdom. J. Small Anim. Pract. 47, 451-455.

Movila, A., Alekseev, A.N., Dubinina, H.V., Toderas, I., 2013. Detection of tick-borne pathogens in ticks from migratory birds in the Baltic region of Russia. Med. Vet. Entomol. 27, $113-117$.

Norte, A.C., lopes de Carvalho, I., Nùncio, M., Ramos, J.A., Gern, L., 2013a. Blackbirds

Turdus merula as competent reservoirs for Borrelia turdi and Borrelia valaisiana in Portugal: evidence from a xenodiagnostic experiment. Environ. Microbiol. 5, 604-607.

Norte, A.C., Ramos, J.A., Gern, L., Nú ncio, M.S., Lopesde Carvalho, I., 2013b. Birds as reservoirs for Borrelia burgdorferi s.l. in Western Europe: circulation of B. turdi and other genospecies in bird-tick cycles in Portugal. Environ. Microbiol. 15, 386-397.

Piesman, J., Gern, L., 2004. Lyme borreliosis in Europe and North America. Parasitology 129, S191-S220.

Schorn, S., Schoel, H., Pfister, K., Silaghi, C., 2011. First record of Ixodes frontalis collected by flagging in Germany. Ticks Tick Borne Dis. 2, 228-230.

Spitalska, E., Literak, I., Kocianova, E., Taragel' ova, V, 2011. The importance of Ixodes arboricola in transmission of Rickettsia spp., Anaplasma phagocytophilum, and Borrelia burgdorferi sensu lato in the Czech Republic, Central Europe. Vector Borne Zoon. Dis. 11, $1235-1241$.

Szé p, T., Mdler, A.P., 2000. Exposure to ectoparasites increases within-brood variability in size and body mass in the sand martin. Oecologia 125, 201-207.

Thorud, C., 1999. Experimentelle Infektion der Vogelzecke Ixodes (Pholeoixodes) arboricola mit Borrelia burgdorferi sensu lato. Dissertation - Hannover 
Van Bronswijk, J.E.M.H., Rijntjes, R.H., Garben, A.F.M., Vos, H., 1979. De teken (Ixodida) van de Benelux-landen. - Amsterdam-Zuid.

White, J., Heylen, D.J.A., Matthysen, E., 2012. Adaptive timing of detachment in a tick parasitizing hole-nesting birds. Parasitology 139, 264-270.

Woo, I.C., Baba, S., Suzuki, H., Kawabata, M., 1990. A case of tick bite with Ixodes turdus. A report from Japan. J. Dermatol. 17, 56-58.

Xu, G., Fang, Q.Q., Keirans, J.E., Durden, L.A., 2003. Molecular phylogenetic analyses indicate that the Ixodes ricinus complex is a paraphyletic group. J. Parasitol. 89, 452-457. Yasuma, A., Baba, S., Shimojima, H., Terui, T., Kawabata, H., 2013. A case of plural tick bites Ixodes turdus occurred in Tokyo. J. Parasitol. 99, 346-349. 
Fig. 1. Coxae I-IV from the developmental stages of three Ixodes species that are often found on songbirds of Western Europe. Column A: Ixodes ricinus, B: I. frontalis, C: I. arboricola. Row 1: nymphs, 2: larvae, 3: males, 4: females. ext: external spur (coxae I-IV); int: internal spur (coxa I)

$1 \mathrm{~A}$

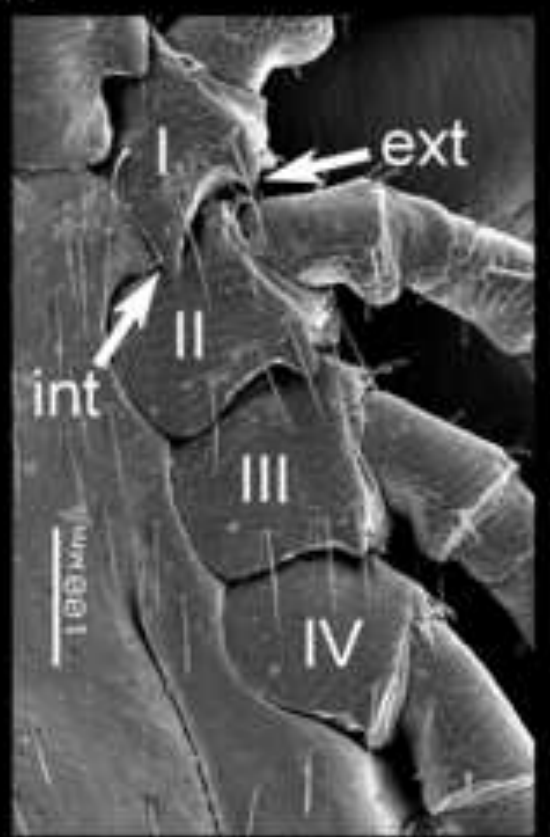

2

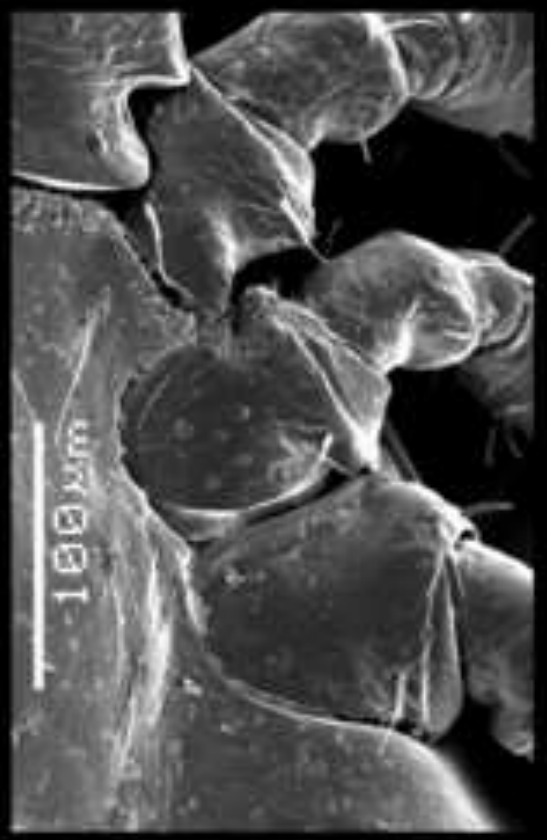

B
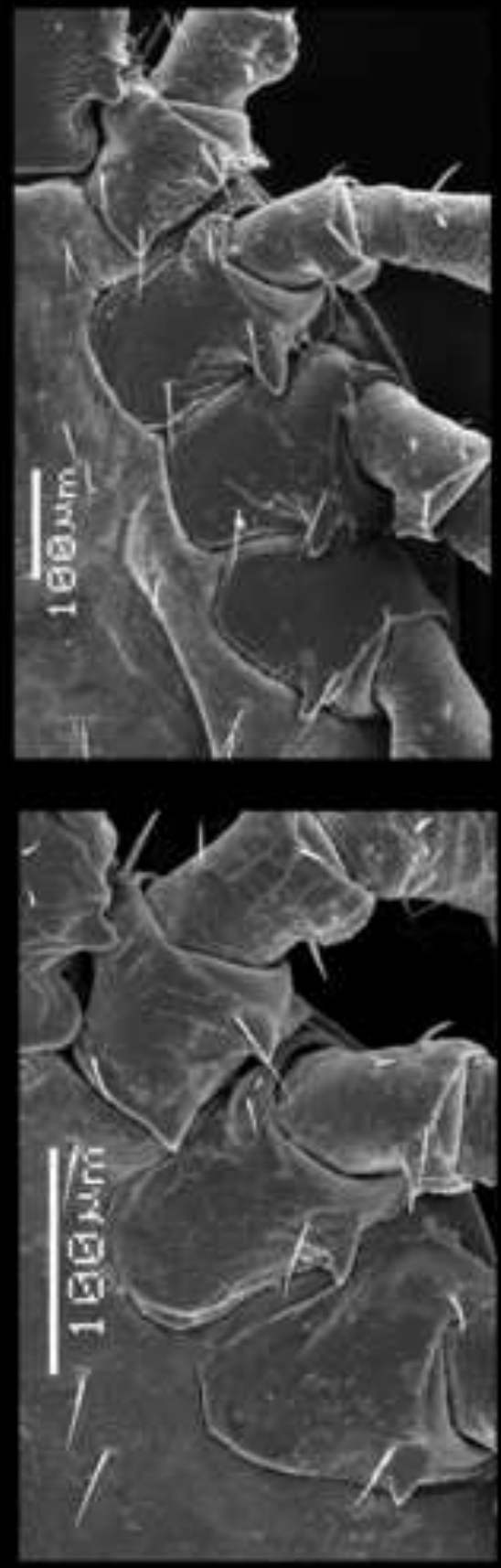

C
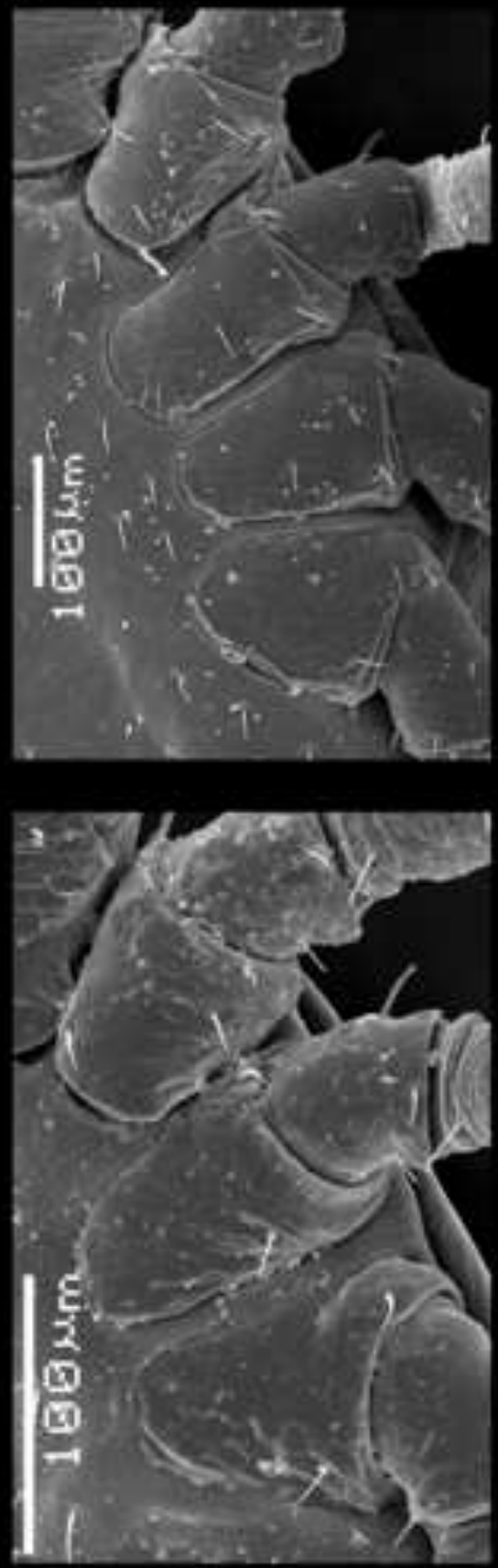
Fig. 2. Ventral aspects of the basis of the capitulum. Column A: Ixodes ricinus, B: I. frontalis, C: I. arboricola. Row 1: adult males, 2: adult females, 3: nymphs, 4: larvae. Arrow indicates position of auricula.

$1 \mathrm{~A}$

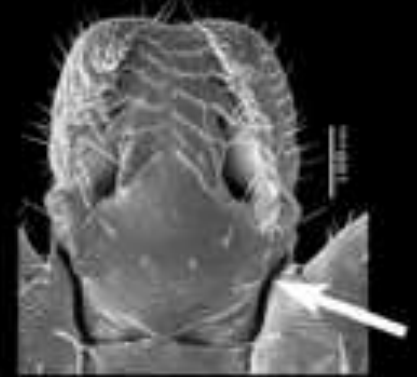

2

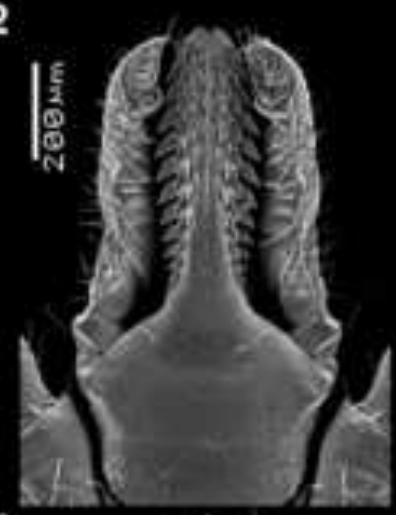

3

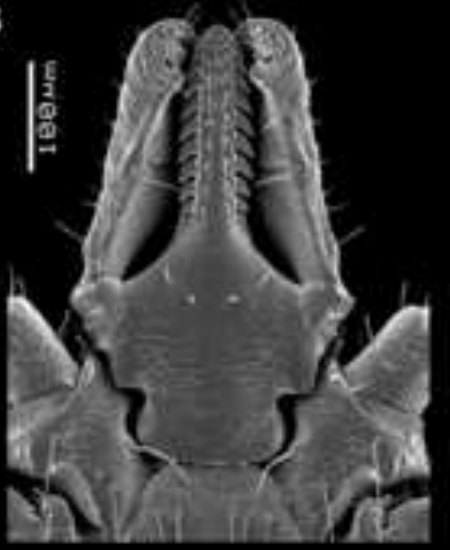

4

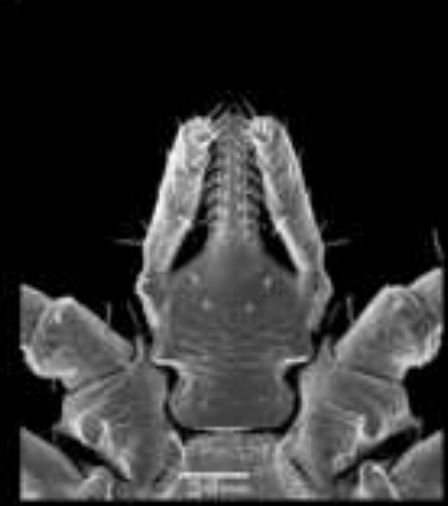

B
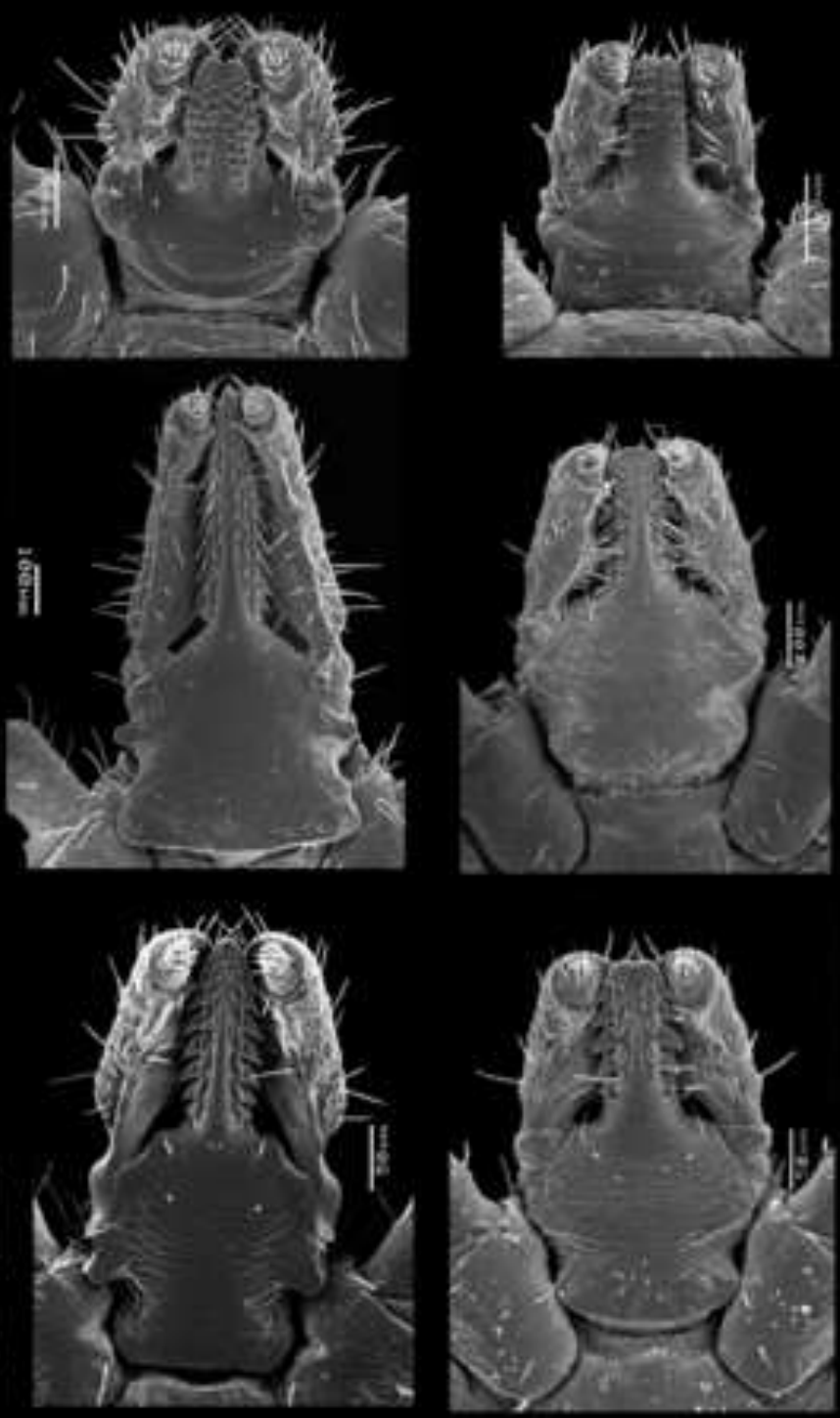

C
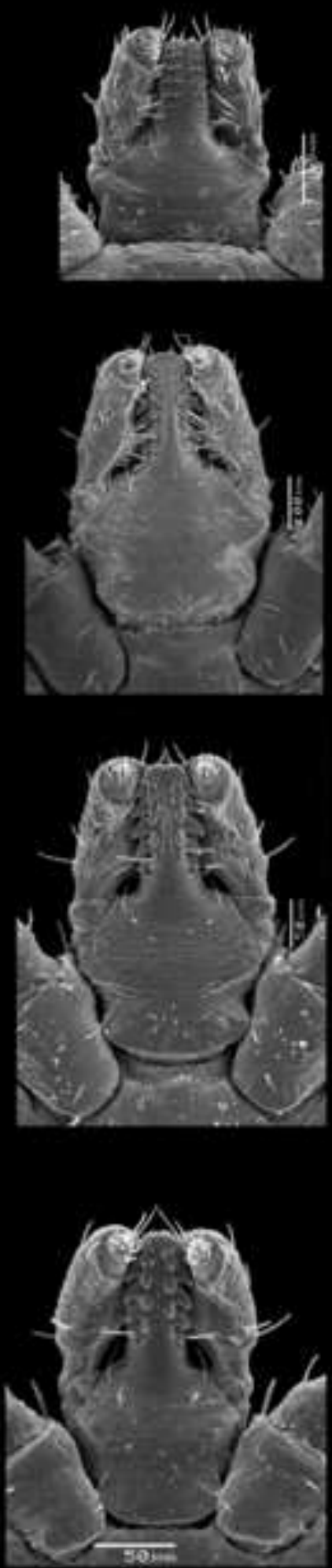
Fig. 3. Ventral (2) overview of the adult males. Column A: Ixodes ricinus, B: I. frontalis, C: I. arboricola. For each species, the tarsus of the first pair of legs is shown (1).

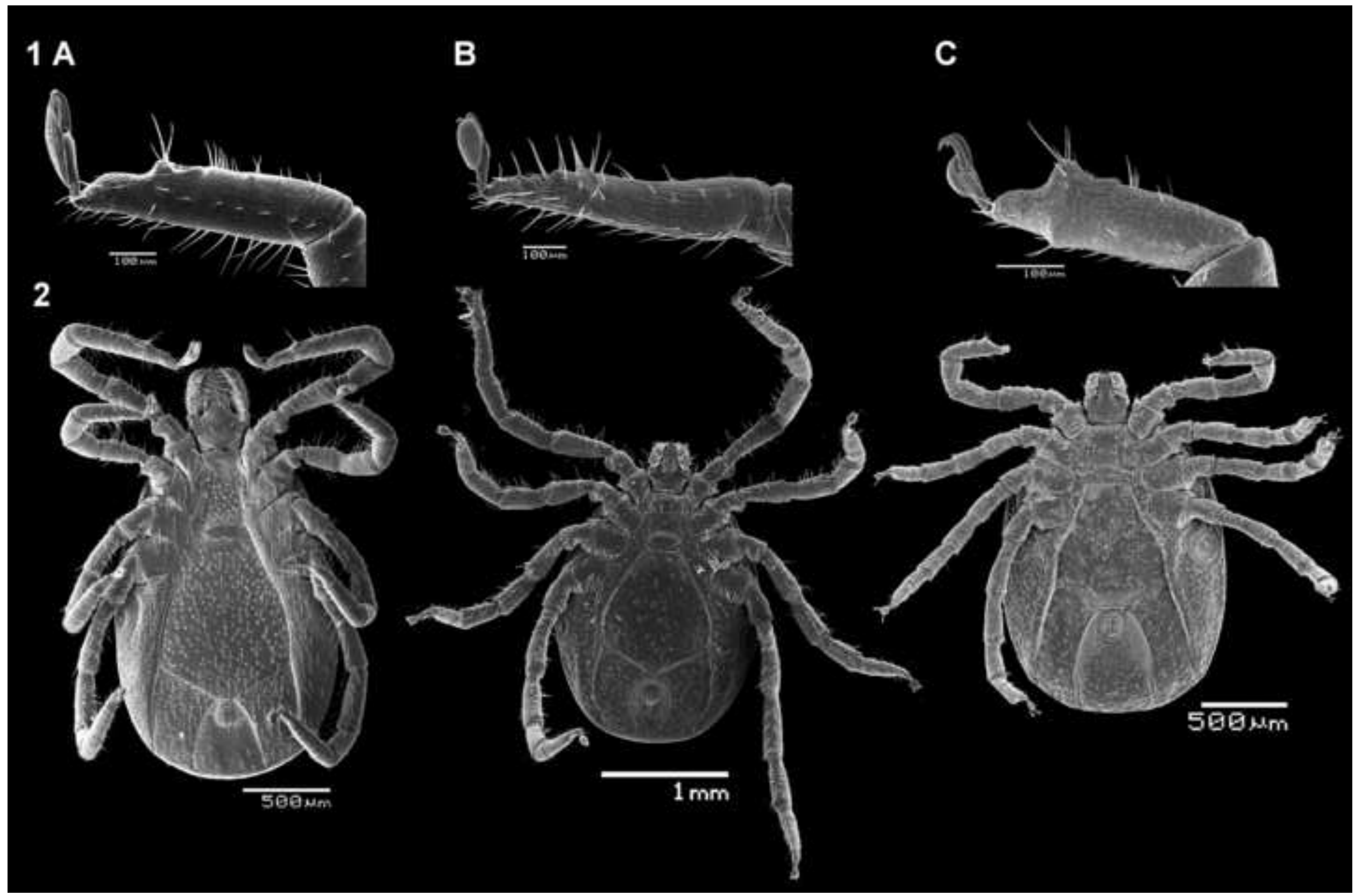


Fig. 4. 16S rDNA average distance tree (values indicate relative genetic distances between 471 isolates). Rhipicephalus appendiculatus Neumann, 1901 was used as outgroup. GenBank accession numbers starting with 'KJ' are from tick individuals that were sampled by D. Heylen and M.Madder

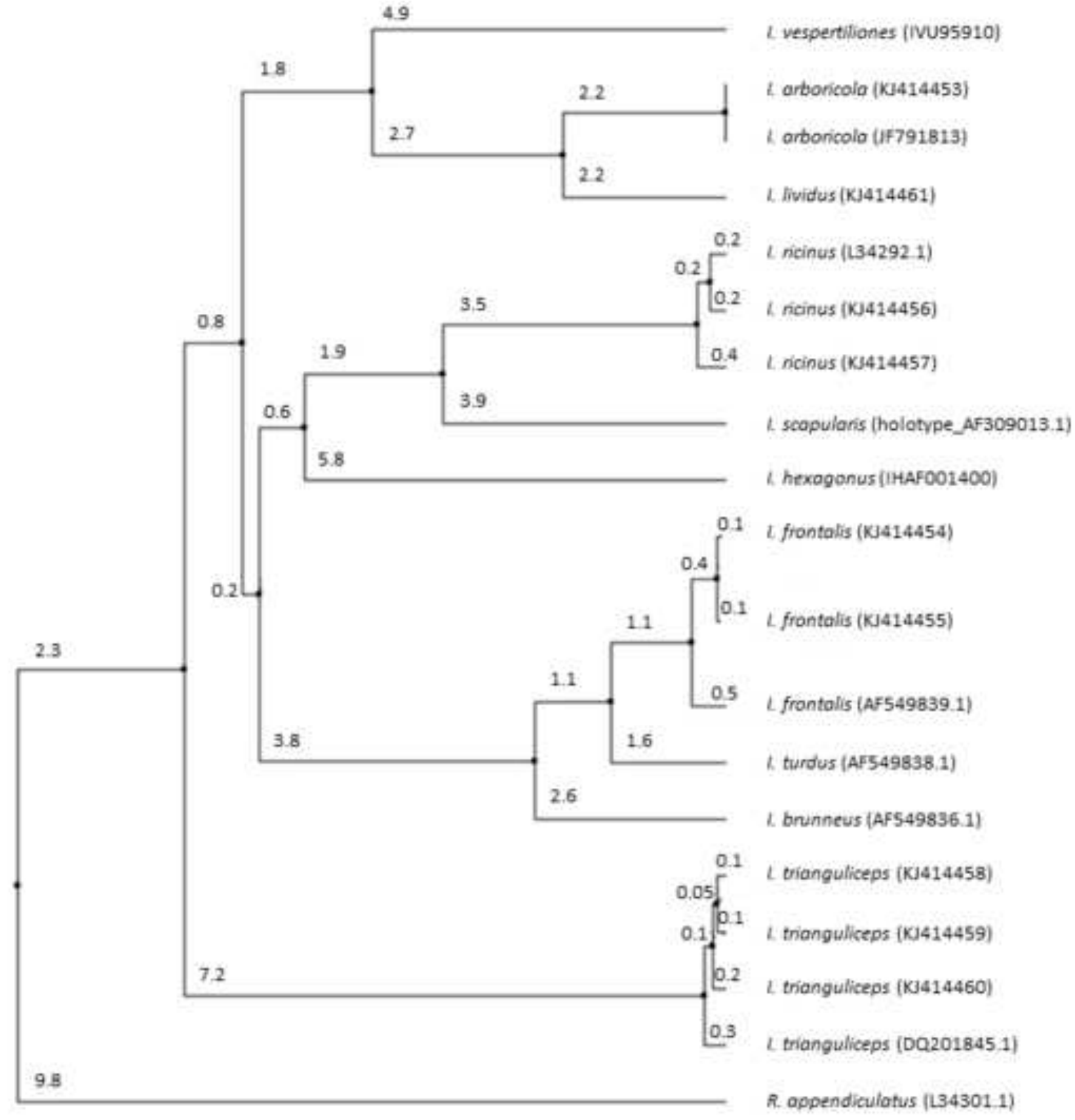


Table 1. Belgian tick (Ixodes) samples used in the phylogenetic analysis. Species, collection locality and date, ITM number and GenBank accession number are listed for each species.

\begin{tabular}{lllll}
\hline \hline Species & Locality (host species) & Date & ITM no. & GenBank no. \\
\hline I. arboricola & nest box (great and blue tit) & February 2008 & ITGIarbocl1 & KJ414453 \\
I. frontalis & mail box (great tit) & August 2010 & ITGIfrontcl1-2 & KJ414454 - 55 \\
I. lividus & bird-derived (bank swallow) & August 2013 & ITGIlivcl1 & KJ414461 \\
I. ricinus & Understory vegetation & March 2012 & ITGIriccl1-2 & KJ414456 - 57 \\
I. trianguliceps & Understory vegetation & April 2012 & ITGItriangcl1-3 & KJ414458 - 60 \\
\hline \hline
\end{tabular}

